\title{
Factors associated with less-than-full-time working in medical practice: results of surveys of five cohorts of UK doctors, 10 years after graduation
}

\author{
Shelly Lachish, Elena Svirko, Michael J. Goldacre and Trevor Lambert ${ }^{*}$
}

\begin{abstract}
Background: The greater participation of women in medicine in recent years, and recent trends showing that doctors of both sexes work fewer hours than in the past, present challenges for medical workforce planning. In this study, we provide a detailed analysis of the characteristics of doctors who choose to work less-than-full-time (LTFT). We aimed to determine the influence of these characteristics on the probability of working LTFT.

Methods: We used data on working patterns obtained from long-term surveys of 10,866 UK-trained doctors. We analysed working patterns at 10 years post-graduation for doctors of five graduating cohorts, 1993, 1996, 1999, 2000 and 2002 (i.e. in the years 2003, 2006, 2009, 2010 and 2012, respectively). We used multivariable binary logistic regression models to examine the influence of a number of personal and professional characteristics on the likelihood of working LTFT in male and female doctors.

Results: Across all cohorts, $42 \%$ of women and $7 \%$ of men worked LTFT. For female doctors, having children significantly increased the likelihood of working LTFT, with greater effects observed for greater numbers of children and for female doctors in non-primary care specialties (non-GPs). While $>40 \%$ of female GPs with children worked LTFT, only $10 \%$ of female surgeons with children did so. Conversely, the presence of children had no effect on male working patterns. Living with a partner increased the odds of LTFT working in women doctors, but decreased the odds of LTFT working in men (independently of children). Women without children were no more likely to work LTFT than were men (with or without children). For both women and men, the highest rates of LTFT working were observed among GPs ( 10 and 6 times greater than non-GPs, respectively), and among those not in training or senior positions.

Conclusions: Family circumstances (children and partner status) affect the working patterns of women and men differently, but both sexes respond similarly to the constraints of their clinical specialty and seniority. Thus, although women doctors comprise the bulk of LTFT workers, gender is just one of several determinants of doctors' working patterns, and wanting to work LTFT is evidently not solely an issue for working mothers.
\end{abstract}

Keywords: Doctors' working patterns, Part-time, Less-than-full-time, Children, Family, Seniority, Specialty, Healthcare workforce planning, Gender differences

\footnotetext{
* Correspondence: trevor.lambert@dph.ox.ac.uk

Nuffield Department of Population Health, UK Medical Careers Research

Group, Unit of Health-Care Epidemiology, University of Oxford, Old Road

Campus, Oxford OX3 7LF, United Kingdom
}

(c) 2016 The Author(s). Open Access This article is distributed under the terms of the Creative Commons Attribution 4.0 International License (http://creativecommons.org/licenses/by/4.0/, which permits unrestricted use, distribution, and reproduction in any medium, provided you give appropriate credit to the original author(s) and the source, provide a link to the Creative Commons license, and indicate if changes were made. The Creative Commons Public Domain Dedication waiver (http://creativecommons.org/publicdomain/zero/1.0/) applies to the data made available in this article, unless otherwise stated. 


\section{Background}

Medical workforce planning is a complex but essential process in the provision of high-quality health services to meet the needs of the population. Along with the number of graduates recruited and the number of doctors retiring or leaving the profession, the level of full-time working is a key determinant of medical workforce supply. Workforce shortages arise not just from an undersupply of doctors to training or consultant posts but also from an increase in the numbers working lessthan-full-time (LTFT) hours.

The persistence of traditional gender roles in society, in which women undertake the bulk of family caring responsibilities, means that female doctors typically work fewer hours than their male counterparts: this pattern transcends medicine [1-3]. Such gendered working patterns are important considerations for medical workforce planners, particularly given women's increasing representation in the medical workforce [2]. Recent studies, however, have shown that doctors of both sexes are working fewer hours than in the past [4-6], with male doctors showing the greater rate of decline in working hours $[7,8]$. In the UK, requests to enter LTFT training have increased, facilitated by recent legislation granting all employees the right to request flexible and LTFT working hours (not just parents) [4, 9]. Authors of some studies have indicated that this move to reduced working hours for doctors represents a cultural shift in valuing time over money and prioritising work-life balance above career progression [7, 10].

Major changes in doctors' working patterns, including the increased use of LTFT work, are a challenge to planning of the long-term provision of effective public health services $[11,12]$. Planning for a sustainable future medical workforce requires detailed knowledge of the characteristics of doctors who choose to work less-than-full-time. Apart from gender, studies have identified several relevant characteristics including family circumstances, marital status and professional specialism [10, 13]. However, most studies have examined sections of the general working population rather than doctors specifically, and many have examined factors in isolation rather than jointly.

Our aim in this study was to determine the relative influence of a number of personal and professional characteristics of doctors on the probability of working LTFT. For this, we used data on working patterns obtained from long-term surveys of more than 11,000 UK-trained doctors.

\section{Methods}

Establishing employment histories and working patterns Since 1975, the UK Medical Careers Research Group has followed the careers of UK doctors by conducting postal and, more recently, web surveys at regular intervals after graduation [14]. The starting point for surveys is the cohort of qualifiers from all UK medical schools in selected years (contact details are supplied by the UK General Medical Council). Cohorts are surveyed towards the end of their first post-graduate year, at 3, 5, 7, 11 years postgraduation, and at longer intervals after that.

Our multipurpose questionnaires ask doctors about topics related to their career and work experiences. Doctors are also asked to provide details of their current and past employment, including the duration and dates of positions, the medical specialty, grade and location of the positions, and whether they were undertaken on a full-time or less-than-full-time basis. For our analyses, we used the position held by each doctor on 30 September of each year to construct an annual employment record. For the small number of respondents who reported multiple concurrent jobs, we included the job with the highest priority based on a 'scoring system' similar to that used by the Department of Health in England (for example, permanent posts were prioritised ahead of locum appointments, posts in medicine were prioritised ahead of posts outside medicine). As doctors provided information on the start and end dates of their jobs, we can populate doctors' annual employment records for the years between our surveys.

We analysed working patterns at 10 years postgraduation (when most doctors are well advanced in a specialty) for doctors of five graduating cohorts, 1993, 1996, 1999, 2000 and 2002. Hence, we analysed the work patterns in the years 2003, 2006, 2009, 2010 and 2012, respectively. Based on information provided by respondents, we had information on employment at 10 years post-graduation for $53 \%$ of the 20,616 doctors who graduated in these five years $(N=10,866$; see Table 1$)$.

\section{Establishing personal and professional characteristics}

In this paper, we have used the term LTFT to denote less-than-full-time training and working, rather than the term 'part-time'. In medical training in the UK, the definition and recognition of LTFT training arises in European Union law (directive EC directive 93/16/EEC, see http://www.aic.lv/ace/ace_disk/Recognition/dir_prof/ SECTORAL/93_16Doct.pdf) and is characterised by being at least $50 \%$ of full-time hours. The term 'part-time' could describe something less formal and, in particular, less than $50 \%$.

To investigate how LTFT working varied across clinical specialties, we aggregated the specialties indicated by respondents in their employment histories into four broad specialty groups: general practice (GP), hospital medical specialties (Hosp), surgical specialties (Surg), and other clinical specialties (Other; see Additional file 1: Table S1).

To assess the influence of seniority on the probability of working LTFT, we categorised the job grades indicated by 
Table 1 Numbers of doctors with known career destinations and working patterns 10 years post-graduation

\begin{tabular}{|c|c|c|c|c|c|c|}
\hline & \multicolumn{5}{|c|}{ Cohort (year of graduation) } & \multirow[b]{2}{*}{ Total } \\
\hline & $1993^{a}$ & 1996 & 1999 & 2000 & $2002^{b}$ & \\
\hline Doctors in the graduating cohort & 3671 & 3868 & 4213 & 4428 & 4436 & 20,616 \\
\hline Doctors with known career destination & 2690 & 1978 & 2226 & 2244 & 2048 & 11,186 \\
\hline Doctors with known working patterns & 2607 & 1886 & 2192 & 2191 & 1990 & 10,866 \\
\hline$\%$ of graduating cohort & 71.0 & 48.8 & 52.0 & 49.5 & 44.9 & 52.7 \\
\hline
\end{tabular}

For those whose employment record at 10 years post-graduation was unknown, we used information on employment at either 9 years post-graduation ( $N=197$ doctors) or at 11 years post-graduation ( $N=94$ doctors)

${ }^{a}$ The 1993 cohort has been surveyed many more times than subsequent cohorts enabling us to hold more extensive information about their careers

${ }^{\text {b}}$ The 2002 cohort has been affected by changes to GMC rules about their permissions for us to contact doctors

respondents in their employment histories as: trainee (post-graduate training grades, including these UK National Health Service (NHS) designations: core trainees, specialist trainees, registrars, house officers, assistants, fellows, tutors), senior (including consultants, principals in general practice, directors, professors), and career (all other grades, notably doctors who had finished specialty training but whose job did not involve the full responsibilities of consultants or principals).

We also asked doctors to answer the following six questions: (i) Did you obtain any qualifications before entering medical school? or (ii) Did you obtain any non-clinical qualifications during medical school?; (iii) Where did you live at the time of your application for medical school?; (iv) Do you live with a spouse or partner?; (v) How many children under 16 reside in your household?; (vi) Are there any dependent adults in your household whose needs affect your ability to pursue your chosen career?

Based on respondents' answers to these questions, we defined the following six factors that we hypothesised may influence the probability that doctors work LTFT: (1) graduate entrant status (binary variable; yes/no), indicating whether the doctor had a degree on entering medical school, and serving as a proxy for age as we did not have accurate age information for many doctors; (2) intercalated degree status (binary variable, yes/no), indicating whether the doctor obtained a research degree during their undergraduate years; (3) family home location at time of entering medical school (binary variable, UK/non-UK); (4) partner status (binary variable, living with spouse or partner/not living with spouse or partner); (5) number of children (ordinal variable with three categories, none, 1, $\geq 2$ ); and (6) dependent adults in the household (binary variable; yes/no). For factors that could change value over time (variables 4, 5, 6 above), we used information given by respondents in the surveys conducted closest to, but following, the 10 years postgraduation time point (for the 1993, 1996, 1999, 2000 and 2002 cohorts, we used data from surveys conducted in 2004, 2007, 2012, 2012 and 2013, respectively).

\section{Statistical analyses}

As a preliminary inspection of the data showed substantially higher rates of LTFT working in female doctors than in males (Table 1), we fitted regression models to female and male data separately. This facilitated both model fitting and parameter interpretation and avoided the need to include higher-order interactions between variables in multivariable models. We used chi-square tests to determine the strength of association between single factors (cohort, specialty, job grade, graduate status, intercalated degree status, family home location, partner status, number of children, and presence of dependent adults) and the probability of working LTFT 10 years post-graduation. Then, to determine the independent influence of the different factors taking account of other factors, and to assess potential interactions among them, we fitted multivariable logistic regression models to our data. Our starting multivariable models included all factors that were associated with LTFT working in univariable testing $(P<0.10)$ and relevant two-way interactions between factors where we hypothesised such interactions would occur (see Appendix for details). Starting models were optimised by backward stepwise elimination of nonsignificant terms, beginning with higher-order interactions using Wald statistics to assess statistical significance of model covariates $(P<0.05)$ and arrive at the minimum adequate models (see Appendix for details). We present odds ratios (with $95 \%$ CI) for the effect of each parameter on the probability of working LTFT in female and male doctors.

\section{Results}

Doctors who were working, or not working, in the NHS

We confine our main analyses, following this short section, to doctors working in the UK National Health Service (NHS; including those with honorary NHS contracts who were predominantly employed in clinical academic posts), because they constituted the vast majority of our dataset and are homogeneous in respect of NHS working conditions (91\%; 9868/10,866; Table 1). 
The 998 doctors working outside the NHS comprised $624(5.7 \%)$ who were working in medicine outside the UK and 291 (2.7\%) who were working in non-NHS UK medicine, with $54(0.5 \%)$ in non-medical employment and $28(0.3 \%)$ not in employment. Among those in medicine abroad, $2.4 \%(213 / 547)$ of men and $19.5 \%$ $(88 / 451)$ of women were working LTFT. Among those in non-NHS UK medicine, $2.2 \%(4 / 181)$ of men and $22.7 \%(25 / 110)$ of women were working LTFT. Small counts do not permit further subgroup analysis of nonNHS doctors.

\section{Doctors working in the NHS}

a) Percentage of doctors working LTFT Across all five cohorts, $42.1 \%$ (95 \% CI 40.8-43.4 \%) of women and $6.7 \%(5.9-7.4 \%)$ of men were working LTFT. In each cohort, LTFT working was far more common among female doctors than among male doctors (Table 2). The proportion of female doctors who worked LTFT at 10 years post-graduation was greater in the two earlier cohorts $(1993,1996)$ than in the three later cohorts (Table 1).

b) Variation in the probability of working LTFT by single factors Results of univariable analyses revealed similarities and differences between female and male doctors in the characteristics associated with the probability of working LTFT (percentages of doctors working LTFT in the different categories are given in Table 2). For both sexes, the probability of working LTFT varied significantly among the five cohorts, among the broad specialty groups, with job grade, and between doctors with and without partners (Table 2). The number of children a doctor had, and to a lesser degree family home location, was associated with the LTFT for women, but not for men (Table 2). Female doctors who worked LTFT had almost twice as many children (mean $=1.7$, $\mathrm{SE}=0.02)$ as females who worked FT (mean $=0.94$ $\mathrm{SE}=0.02 ; P<0.001)$, unlike their male colleagues $(\mathrm{FT}=1.34 \mathrm{SE}=0.07 ; \mathrm{LTFT}=1.38, \mathrm{SE}=0.02 ; P=0.51)$. Graduate status, and to a lesser degree intercalated degree status, was associated with the probability of working LTFT only for men; graduates and those with intercalated degrees were more likely to work LTFT (Table 2).

c) Multivariable analysis of the probability of working LTFT

Multivariable models confirmed that for both men and women, the highest rates of LTFT working were observed among GPs (Fig. 1). The odds of working LTFT were on average 10 times higher for female
GPs than for female non-GPs, and on average 6 times higher for male GPs than for male non-GPs (Table 3; Fig. 1). There was much less variation by gender in the probability of working LTFT among the three non-primary care specialty groups (Table 3; Fig. 1).

Models also showed that the presence of children in the family home increased the probability that female doctors worked LTFT and that the extent to which children affected LTFT working differed by specialty group (Table 3). Compared to female GPs with no children, female GPs with one child were on average four times as likely to be working LTFT, while those with two or more children were on average eight times as likely to be working LTFT (Table 3; Fig. 1). For females in the non-primary care specialties, the presence of children increased the likelihood of working LTFT over those without children to a far higher degree (Table 3). Nonetheless, predicted rates of LTFT working with children were still lower for females in non-primary care than for female GPs (Fig. 1). For example, while $>40 \%$ of female GPs with one child worked LTFT, only $10 \%$ of female surgeons with one child did so (Fig. 1). Importantly, the working patterns of female doctors with no children did not differ significantly from those of male doctors (with or without children) in any of the specialty groups (Fig. 1).

Among women, the effect of having children on the likelihood of working LTFT varied marginally according to job grade $(P=0.03$; Table 3$)$. Both male and female doctors in 'career' grade jobs were more likely to work LTFT than were doctors in trainee positions or in senior positions (Table 3, Fig. 2). Children, however, increased the likelihood of working LTFT to a greater degree for female trainees than for females in higher-level positions (Table 3, Fig. 2). While women were more likely to be in career grade positions than men ( 28 vs $11 \%$ ), $50 \%$ of doctors in trainee and senior positions were women. There was no evidence of an interaction between job grade and clinical specialty for either sex (see Appendix).

The working patterns of both sexes were affected by the presence of a partner, but in opposite ways. Living with a partner increased the odds of LTFT working in females by $31 \%$, but decreased the odds of LTFT working in males by $54 \%$ (Table 3 ). The effect of partner status on working LTFT did not differ by clinical specialty, family home location (for female doctors) or graduate status (for male doctors; see Appendix). However, male doctors who were graduate entrants to medical school, and thus on average older than non-graduate entrants, were twice as likely to work LTFT as were those who had not undertaken a prior degree (odds ratio $=2.0$, CI 1.3-2.9; Table 3). 
Table 2 Percentages of doctors in different categories working less-than-full-time (LTFT), 10 years post-graduation

\begin{tabular}{|c|c|c|c|c|}
\hline \multirow[b]{2}{*}{ Categories } & \multicolumn{2}{|l|}{ Females } & \multicolumn{2}{|l|}{ Males } \\
\hline & $\%$ LTFT & Number & $\%$ LTFT & Number \\
\hline \multicolumn{5}{|l|}{ Cohort } \\
\hline 1993 & 50.3 & 1164 & 6.4 & 1161 \\
\hline 1996 & 51.8 & 926 & 10.2 & 804 \\
\hline 1999 & 36.6 & 1077 & 5.3 & 905 \\
\hline 2000 & 39.3 & 1089 & 4.8 & 912 \\
\hline 2002 & 33.5 & 1112 & 7.1 & 718 \\
\hline Chi-square & $X^{2}{ }_{4}=119.5, P<0.001$ & & $x_{4}^{2}=24.2, P<0.001$ & \\
\hline \multicolumn{5}{|l|}{ Specialty group } \\
\hline General practice & 61.7 & 2360 & 15.7 & 1245 \\
\hline Hospital specialties & 28.3 & 735 & 3.0 & 804 \\
\hline Surgical specialties & 19.0 & 605 & 2.0 & 1148 \\
\hline Other specialties & 28.7 & 1615 & 4.0 & 1286 \\
\hline Chi-square & $X^{2}{ }_{3}=679.1, P<0.001$ & & $X^{2}{ }_{3}=239.5, P<0.001$ & \\
\hline \multicolumn{5}{|l|}{ Job grade } \\
\hline Senior & 41.6 & 1580 & 8.0 & 1591 \\
\hline Career & 62.9 & 1484 & 20.0 & 515 \\
\hline Trainee & 29.4 & 2188 & 2.6 & 2270 \\
\hline Chi-square & $x_{2}^{2}=406.9, P<0.001$ & & $x_{2}^{2}=215.5, P<0.001$ & \\
\hline \multicolumn{5}{|l|}{ Family home location } \\
\hline UK & 42.8 & 4941 & 6.8 & 4028 \\
\hline Non-UK & 34.2 & 158 & 6.1 & 131 \\
\hline Chi-square & $x_{2}^{2}=4.4, P=0.04$ & & $X_{2}^{2}=0.02, P=0.90$ & \\
\hline \multicolumn{5}{|l|}{ Intercalated degree } \\
\hline Yes & 41.9 & 1863 & 5.6 & 1814 \\
\hline No & 40.9 & 2578 & 7.5 & 1865 \\
\hline Chi-square & $x_{2}^{2}=0.3, P=0.60$ & & $x_{2}^{2}=5.0, P=0.03$ & \\
\hline \multicolumn{5}{|l|}{ Graduate status } \\
\hline Yes & 44.8 & 362 & 11.5 & 358 \\
\hline No & 42.5 & 4741 & 6.3 & 3831 \\
\hline Chi-square & $x_{2}^{2}=0.6, P=0.43$ & & $X_{2}^{2}=13.3, P=<0.001$ & \\
\hline \multicolumn{5}{|l|}{ Living with spouse } \\
\hline Yes & 46.4 & 4420 & 6.1 & 3876 \\
\hline No & 18.9 & 813 & 10.2 & 482 \\
\hline Chi-square & $x_{2}^{2}=210.6, P=<0.001$ & & $X_{2}^{2}=11.0, P=0.001$ & \\
\hline \multicolumn{5}{|l|}{ Children } \\
\hline None & 18.0 & 1635 & 7.6 & 1275 \\
\hline One & 38.7 & 1090 & 6.7 & 871 \\
\hline Two or more & 61.1 & 2413 & 5.9 & 2155 \\
\hline Chi-square & $X_{2}^{2}=750.5, P=<0.001$ & & $x_{2}^{2}=3.6, P=0.16$ & \\
\hline \multicolumn{5}{|l|}{ Dependent adults } \\
\hline Yes & 40.2 & 423 & 7.9 & 304 \\
\hline No & 42.4 & 4582 & 6.6 & 3856 \\
\hline Chi-square & $x_{2}^{2}=0.7, P=0.40$ & & $x_{2}^{2}=0.6, P=0.44$ & \\
\hline
\end{tabular}




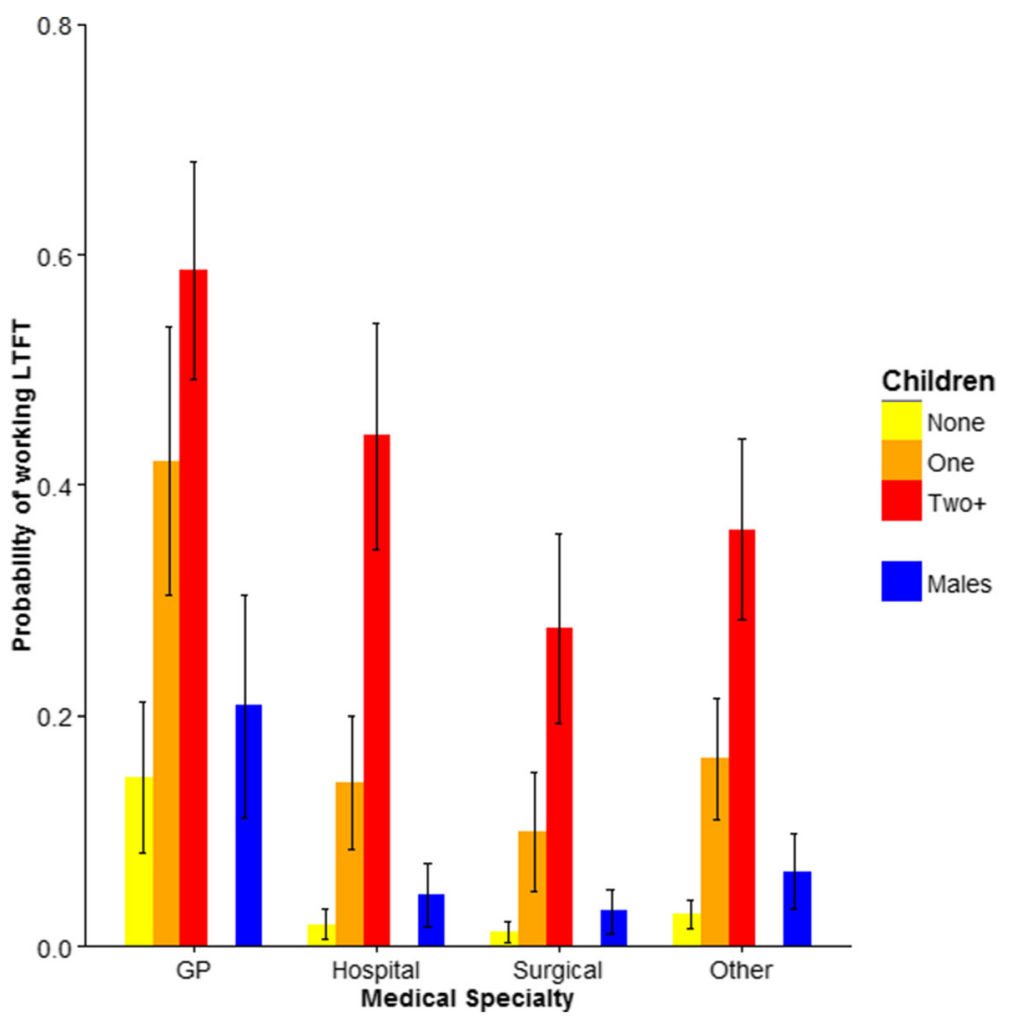

Fig. 1 Effect of children on the probability of female doctors in different medical specialties working LTFT. Also shown are the probabilities of working LTFT for male doctors in those specialties (in blue). The plotted predicted probabilities were obtained from multivariable models parameterised for the 2002 cohort with the other covariates held at their reference value (i.e. not living with a spouse/trainee job grade/non-graduate)

\section{Discussion}

In this study of practising doctors, almost half of the women $(42 \%)$ but few men $(7 \%)$ worked LTFT. We showed that a substantial proportion of this gender variation in doctors' working patterns could be attributed to the presence of children and a spouse in the family home. Moreover, our study also showed that while family circumstances (children and partner status) affect male and female doctors' working patterns in contrasting ways, professional circumstances (specialty and seniority) influence working patterns in similar ways for both sexes.

Child-rearing responsibilities strongly influenced the probability that female doctors worked LTFT, with substantially greater effects associated with greater numbers of children, but had no effect on the likelihood that male doctors worked LTFT. Indeed, $88 \%$ of the female doctors who worked LTFT in this study had children compared with just $65 \%$ of the male doctors who worked LTFT. Living with a spouse increased the likelihood that female doctors worked LTFT (independently of whether they had children), but decreased the likelihood that male doctors worked LTFT. These results support previous studies showing that parenthood and marriage decrease female doctors' working hours, but increase or have a negligible effect on men's working hours [7, 10, 12, 13, 15]. Hence, our work provides further evidence that the persisting female-male difference in LTFT is probably due to persisting unequal division of domestic responsibilities: women in domestic partnerships or with children spend less time at work than men with similar responsibilities $[7,10,16$, 17]. Accordingly, one may surmise, though we do not have direct evidence to support the conjecture, that men, more than women, work LTFT for reasons other than family commitments. Importantly, we showed that female doctors with no children were no more likely to work LTFT than were male doctors, with or without children. This strengthens the notion that female doctors' working patterns (FT vs LTFT) are largely driven by family caring commitments [18]. This is an essential consideration for workforce planners seeking novel training and employment strategies to accommodate increasing numbers of women within medicine, particularly as studies show that female doctors with older children work as many hours as their male colleagues $[19,20]$.

A key finding of this study was that the association of LTFT working with having children differed by clinical specialty, with stronger effects for female doctors working in non-primary care than for GPs. Almost all female 
Table 3 Multivariable effects of personal and professional characteristics on probability that doctors work LTFT, 10-years post-graduation

\begin{tabular}{|c|c|c|c|c|}
\hline \multirow[b]{2}{*}{ Model terms ${ }^{a}$} & \multicolumn{2}{|l|}{ Females $^{\mathrm{b}}$} & \multicolumn{2}{|l|}{ Males $^{c}$} \\
\hline & $\overline{\text { Wald } x^{2}}$ & Odds ratio $(95 \% \mathrm{Cl})$ & Wald $x^{2}$ & Odds ratio $(95 \% \mathrm{Cl})$ \\
\hline Cohort [2002] & $x^{2}=172, d f=4, P<0.001$ & 1.00 & $x^{2}=18.9, \mathrm{df}=4, P<0.001$ & 1.00 \\
\hline 1993 & & $2.53(2.05-3.12)$ & & $0.83(0.55-1.28)$ \\
\hline 1996 & & $2.71(2.17-3.39)$ & & $1.31(0.86-2.01)$ \\
\hline 1999 & & $0.93(0.75-1.14)$ & & $0.70(0.43-1.12)$ \\
\hline 2000 & & $1.17(0.95-1.44)$ & & $0.54(0.33-0.88)$ \\
\hline Specialty [GP] & $x^{2}=103.0, \mathrm{df}=3, P<0.001$ & 1.00 & $X^{2}=89.2, d f=3, P<0.001$ & 1.00 \\
\hline Hospital & & $0.11(0.06-0.21)$ & & $0.18(0.10-0.30)$ \\
\hline Surgical & & $0.07(0.03-0.15)$ & & $0.12(0.07-0.20)$ \\
\hline Other & & $0.16(0.10-0.25)$ & & $0.26(0.18-0.39)$ \\
\hline Job Grade [Trainee] & $x^{2}=37.5, \mathrm{df}=2, P<0.001$ & 1.00 & $x^{2}=60.6, \mathrm{df}=2, P<0.001$ & 1.00 \\
\hline Career & & $3.53(2.14-5.86)$ & & $3.51(2.30-5.39)$ \\
\hline Senior & & $1.50(0.91-2.49)$ & & $1.11(0.73-1.69)$ \\
\hline Living with Spouse [No] & $X^{2}=4.10, d f=1, P=0.04$ & 1.00 & $x^{2}=16.3, d f=1, P<0.001$ & 1.00 \\
\hline Yes & & $1.31(1.01-1.71)$ & & $0.46(0.32-0.68)$ \\
\hline Graduate Status [No] & NA & NA & $X^{2}=11.1, \mathrm{df}=1, P<0.001$ & 1.00 \\
\hline Yes & & NA & & $1.96(1.30-2.89)$ \\
\hline Children [None] & $x^{2}=52.6, \mathrm{df}=2, P<0.001$ & 1.00 & NA & NA \\
\hline One & & $4.23(2.24-8.05)$ & & NA \\
\hline Two or more & & $8.26(4.66-14.74)$ & & NA \\
\hline Specialty*Children [GP*None] & $x^{2}=28.6, \mathrm{df}=6, P<0.001$ & 1.00 & NA & NA \\
\hline Hospital*1 & & $1.99(0.92-4.50)$ & & NA \\
\hline Surgical*1 & & $2.06(0.80-5.71)$ & & NA \\
\hline Other*1 & & $1.62(0.91-2.92)$ & & NA \\
\hline Hospital*2+ & & $4.91(2.46-10.41)$ & & NA \\
\hline Surgical ${ }^{*} 2+$ & & $3.66(1.60-9.30)$ & & NA \\
\hline Other ${ }^{*} 2+$ & & $2.43(1.46-4.09)$ & & NA \\
\hline JobGrade*Children [Trainee*None] & $x^{2}=11.0, d f=4, P=0.03$ & 1.00 & NA & \\
\hline Career*1 & & $0.43(0.23-0.83)$ & & NA \\
\hline Senior*1 & & $0.49(0.26-0.93)$ & & NA \\
\hline Career*2+ & & $0.41(0.23-0.73)$ & & NA \\
\hline Senior*2+ & & $0.39(0.22-0.70)$ & & NA \\
\hline
\end{tabular}

Results of separate multivariable logistic regression models performed for female and male doctors: terms with 'NA' in cells were not included in the final model for that sex

${ }^{\mathrm{a}}$ The reference category of each model term and interaction is given in square brackets

${ }^{b}$ The final model for female doctors was [ Cohort+JobGrade+Spouse+Specialty*Children+JobGrade*Children]

'The final model for male doctors was [ Cohort+JobGrade+Spouse+Specialty+GradStatus]

non-primary care specialists who worked LTFT had children (93\%; compared to $81 \%$ for female GPs). However, women in non-primary care specialties were far less likely to work LTFT than were female GPs with children (e.g. $68 \%$ of female GPs with children worked LTFT compared with just $33 \%$ of female surgeons with children). These are important findings for workforce planners. Previous studies have not directly assessed how the effect of children on doctor's working patterns varies by specialty. However, several studies have reported higher rates of LTFT working among GPs than among doctors working in other specialties $[7,15,21]$. Here too, we found that GPs were far more likely to work LTFT than other specialty doctors. This was true for both male and female doctors. As we controlled for job grade in our models, the observed differences between specialty groups cannot be explained by variation in the 'seniority' of doctors among specialties. Rather, different rates of LTFT working in different specialties occur because specialties differ in demographic composition (e.g. female 


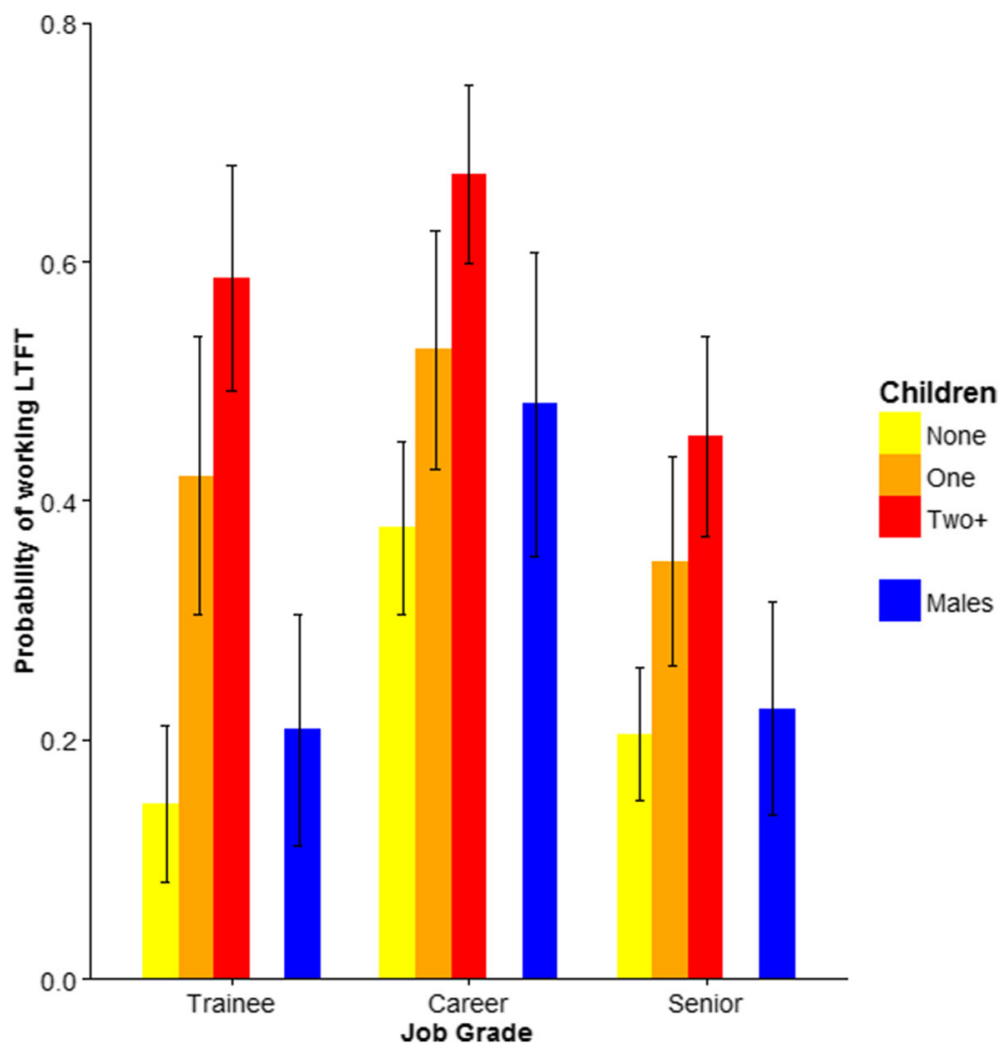

Fig. 2 Effect of children on the probability of female doctors in different job grades working LTFT. Also shown are the probabilities of working LTFT for male doctors in those job grades (Trainee, Career, Senior). Predicted probabilities obtained from multivariable models parameterised for the 2002 cohort. Other covariates in models were held at their reference values: GP/not living with spouse/non-graduates)

doctors comprised $60 \%$ of GPs in this study, but only $35 \%$ of surgeons) and in organisational structure (there are greater opportunities for working reduced hours in GP than in most hospital-based specialties). Thus, while personal circumstances may drive doctors' choices for particular specialties [22], the nature of some specialties may, equally, facilitate particular life choices [6, 17]. Long-term studies examining changes in career preferences, family responsibilities and work outcomes among male and female doctors are needed to disentangle these two possibilities.

Compared to general practice, the provision of LTFT posts in non-primary care specialties is a relatively recent phenomenon. Efforts to provide flexible working and LTFT posts in specialties other than GP in the UK and elsewhere have improved [4]. Nevertheless, our results showing that far fewer female doctors with children work LTFT in the hospital and surgical specialties than in GP and that almost all the LTFT posts in nonprimary care are occupied by women with children, suggesting that needs are still not being adequately met in these areas. For female doctors, the possibility of accommodating work and family responsibilities via a LTFT working pattern remains strongly constrained by opportunities to do so in particular specialities [17]. Moreover, as some male GPs and female GPs with no children also work LTFT (Fig. 1), a desire for reduced working patterns is evidently not solely a concern for working mothers. Further research in this field should aim to understand the motivations of doctors without children who work LTFT hours in individual medical specialties: small sample sizes in individual specialties precluded our doing so in this study.

Doctors in trainee and senior positions were less likely to work LTFT than their colleagues in other positions. This contrasts with previous studies showing larger gender differences in LTFT working rates with career progression [23, 24]. Our finding of lower rates of LTFT working for trainees probably reflects the fact that meeting training requirements can be difficult when working LTFT. Medical training is a lengthy process that many doctors do not wish to prolong [25]. In senior positions, LTFT working is challenging, given the greater responsibility, higher workload, lack of specialist expertise cover, and greater administration and management duties involved [24]. After completing specialty training, some doctors may consciously forego senior positions for 'career' grade positions that enable 
them to better balance work and life commitments. In the UK between 2000 and 2010, the number of salaried GPs (which we included in our 'career' grade categorisation for analyses) increased tenfold, while the number of principal (senior) GPs declined [26]. This was attributed to a desire among younger GPs for increased working flexibility. Interestingly, our results showed that female doctors with children in trainee positions were more likely to work LTFT than females in higherlevel positions. Although the reasons for this are not clear, ensuring that women with family caring responsibilities are accommodated at all stages of their career is an important consideration for future workforce planners [24].

Our analyses suggest that the effect of seniority on working patterns was not driven by age differences among the doctors. Studies examining doctors' working patterns commonly report that younger and older doctors work fewer hours than middle-aged doctors [7]. Having examined working patterns of doctors at a fixed point in their career, we anticipated less variation in doctors' ages in our study than occurs in cross-sectional studies covering a wide age range. However, we found that men who were graduate entrants to medical school (and thus on average older than non-graduate entrants) were more likely to work LTFT. Graduate entrants to medical school (and older doctors in general) may be more financially secure if they pursued careers in other fields and have continued interests or responsibilities in areas outside medicine. These factors help explain the increased propensity of male graduate entrants to work LTFT hours, but not why this effect was only present for males. Further work is needed to identify the motivations and career preferences that drive male doctors' decisions to work LTFT.

Several studies from the UK $[9,19]$ and elsewhere $[5,27]$ have reported increasing rates of LTFT working among doctors over past decades. As we examined the working patterns of just five cohorts of medical graduates over a 9-year period (2003 to 2012) at a fixed point in their career (10 years after graduation), our results are not directly comparable to these previous studies. Nevertheless, we observed a decrease in the proportion of female doctors working LTFT in the three later cohorts (1999, 2000 and 2002), with no change in males. Examination of our data do not suggest this change was driven by changes among females in one particular specialty group, though small sample sizes precluded statistical testing of this suggestion. Moreover, this change did not appear to be driven by later cohorts having fewer children or delaying starting a family (females in the five cohorts did not differ in the average number of children they had or the average number of years they had been mothers). An alternative possibility is that the implementation of the European Working Time Directive in 2009, which mandated the reduction of working hours for doctors, and the increased options to work 'flexibly' in recent years (e.g. longer hours over fewer days), could have enabled some women with caring responsibilities to balance work-life commitments while remaining essentially 'full-time' [28]. Verification of this suggestion and a more thorough exploration of trends in the working patterns of female doctors should be a critical component of planning effective alternative working strategies for the workforce. While women constitute a growing proportion of the medical workforce, working doctors of both sexes increasingly express desires to work fewer hours and for working circumstances that allow time for non-work-related pursuits $[9,29]$. This changing face of the medical workforce is a challenge for future effective workforce planning that is facilitated by a greater understanding of the drivers of doctors' decisions regarding their working patterns.

This study investigated working patterns in a very large number of doctors from across the UK over a 9-year period using information on working patterns obtained independently of any organisation that employs, trains or influences doctors' careers. Nevertheless, there are limitations to our study. First, we evaluated working patterns in terms of a full-time versus less-than-full-time dichotomy as survey respondents did not specify their weekly hours worked. Examining correlates of hours worked may provide a more nuanced understanding of the drivers of doctors' working patterns. Second, there may be additional reasons to those we examined influencing doctors' working patterns. Doctors with concurrent managerial or academic roles, those with health problems or other responsibilities (e.g. sporting or community roles) may only work LTFT in medicine. Third, we assessed working patterns at a fixed point in the doctors' careers. Understanding how drivers of working patterns change throughout doctors' careers will require longer-term, continuous monitoring of the employment status, personal and professional characteristics of large numbers of doctors (the subject of our ongoing research). Finally, data on working patterns were derived from self-reported information given in response to surveys. Confidentiality precludes substantiation of the veracity of respondents' responses, but respondents gained nothing by submitting erroneous data. We cannot, however, discount the potential that non-responders may over-represent those taking nontypical career options.

\section{Conclusions}

We have shown that while family circumstances affect female and male working patterns differently, both sexes respond similarly to the circumstances of their 
professional niche. Thus, although women comprise the majority of LTFT workers in medicine, gender is just one of several determinants of doctors' working patterns. Given the growing percentage of women in the medical workforce, and as doctors who work LTFT report being less stressed and more satisfied at work [30], it is time for public health services to acknowledge that LTFT medical careers are here to stay. At the least this should involve creating LTFT appointments across the breadth of medical specialties, implementing policies that encourage women to return to full-time work, and establishing legitimate career paths that enable doctors of both sexes to train and work LTFT.

\section{Appendix}

\section{Multivariable modelling methods}

On the basis of the results of univariable results presented in Table 2, we constructed multivariable models to explain variation in LTFT working.

For female doctors, our starting model contained the additive effects of cohort, specialty, job grade, family home, partner status and number of children, along with eight interactions between covariates (specialty"job grade, specialty"partner, specialty"children, specialty*family home, children*job grade, children"family home, partner"family home, and partner"children). For male doctors our starting model contained the effect of cohort, specialty, job grade, partner status, graduate status and degree status, along with four interactions (specialty*job grade, specialty* partner status, specialty*graduate status, and graduate status*partner status). Small sample sizes in some category combinations precluded inclusion of higher order interactions.

These full starting models were optimised by backward stepwise elimination of nonsignificant terms, beginning with higher order interactions and using Wald's statistics to assess statistical significance of the model covariates $(P<0.05)$ and arrive at the minimum adequate models. To verify the minimum models, variables not originally selected were added back one at a time to confirm their effects remained negligible in the presence of potential confounders.

After model simplification, the minimum adequate model for female doctors contained the additive effects of cohort, specialty, job grade, partner status and number of children, with the effect of children varying both by specialty and by job grade (Table 4). The minimum adequate model explaining variation in probability of working LTFT for male doctors contained only the additive effects of cohort, specialty, job grade, partner status and graduate status (Table 5). Adding any of the excluded factors back in to these models did not improve model fit.
Table 4 Model simplification by backwards stepwise selection of multivariable binary logistic model to assess effects of personal and professional characteristics on the probability of working less-than-full-time, 10 years post-graduation, for female doctors

\begin{tabular}{|c|c|c|c|c|}
\hline \multirow{2}{*}{$\begin{array}{l}\text { Model selection } \\
\text { steps }\end{array}$} & \multirow[t]{2}{*}{ Terms removed } & \multicolumn{3}{|c|}{ Wald's test $^{a}$} \\
\hline & & $x^{2}$ & $\mathrm{df}$ & $P$ \\
\hline $\begin{array}{l}1 \text { (Starting } \\
\text { model) }\end{array}$ & $\begin{array}{l}\text { Cohort+Specialty+Children+JobGrade+ } \\
\text { Spouse+FamilyHome+Specialty*Children+ } \\
\text { Specialty*Spouse+Specialty*FamilyHome+ } \\
\text { Specialty*JobGrade+JobGrade*Children+ } \\
\text { Spouse*Children+Children*FamilyHome+ } \\
\text { Spouse*FamilyHome }\end{array}$ & & & \\
\hline 2 & - Specialty*Spouse & 0.47 & 3 & 0.93 \\
\hline 3 & - FamilyHome* Children & 0.61 & 2 & 0.74 \\
\hline 4 & - FamilyHome*Spouse & 0.00 & 1 & 0.99 \\
\hline 5 & - Specialty*FamilyHome & 1.60 & 3 & 0.65 \\
\hline 6 & - Specialty*JobGrade & 4.30 & 6 & 0.63 \\
\hline 7 & - Spouse*Children & 1.70 & 2 & 0.44 \\
\hline 8 & - FamilyHome & 0.01 & 1 & 0.94 \\
\hline 7 & - Spouse*Children & 1.70 & 2 & 0.44 \\
\hline 8 & - FamilyHome & 0.01 & 1 & 0.94 \\
\hline
\end{tabular}

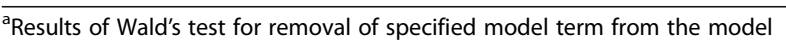

Table 5 Model simplification by backwards stepwise selection of multivariable binary logistic model to assess effects of personal and professional characteristics on the probability of working less-than-full-time, 10 years post-graduation, for male doctors selection

\begin{tabular}{|c|c|c|c|c|}
\hline \multirow{2}{*}{$\begin{array}{l}\text { Model selection } \\
\text { steps }\end{array}$} & \multirow[t]{2}{*}{ Terms/terms removed } & \multicolumn{3}{|c|}{ Wald's test ${ }^{a}$} \\
\hline & & $x^{2}$ & df & $P$ \\
\hline 1 (Full model) & $\begin{array}{l}\text { Cohort+Specialty+JobGrade+ } \\
\text { Spouse+Intercalated Degree+ } \\
\text { Graduate+Specialty*JobGrade+ } \\
\text { Specialty*Graduate+Specialty* } \\
\text { Spouse+Graduate*Spouse }\end{array}$ & & & \\
\hline 2 & - Graduate*Spouse & 0.02 & 1 & 0.88 \\
\hline 3 & - Specialty*Graduate & 3.00 & 3 & 0.39 \\
\hline 4 & - Specialty*Spouse & 3.40 & 3 & 0.34 \\
\hline 5 & - Intercalated Degree & 0.07 & 1 & 0.79 \\
\hline 6 & - Specialty*JobGrade & 11.5 & 6 & 0.07 \\
\hline
\end{tabular}




\section{Additional file}

Additional file 1: Table S1. Broad specialty groups used in analyses and 483 the individual specialties in 484 each group. (DOCX $11 \mathrm{~kb}$ )

\section{Acknowledgements}

We thank Janet Justice and Alison Stockford for data entry. We are very grateful to all the doctors who participated in the surveys.

\section{Funding}

This is an independent report commissioned and funded by the Policy Research Programme in the Department of Health (project number 016/ 0118). The views expressed in this publication are those of the authors and not necessarily those of the Department of Health.

\section{Availability of data and materials}

It may be possible for the authors to make tabulated data, produced in the course of this work but not included in the paper, available to interested readers on request.

\section{Authors' contributions}

All authors had full access to all the data (including statistical reports and tables) in the study and take responsibility for the integrity of the data and the accuracy of the data analysis. MJG and TWL planned and designed the surveys. ES, SL and TWL planned the data analysis. ES and SL undertook the data analysis. SL wrote the first draft of the paper and all authors contributed to further drafts and approved the final version. All authors read and approved the final manuscript.

\section{Competing interests}

The authors declare that they have no competing interests.

\section{Ethics approval and consent to participate}

National Research Ethics Service, following referral to the Brighton and Mid-Sussex Research Ethics Committee in its role as a multi-centre research ethics committee (ref 04/Q1907/48 amendment Am02 March 2015).

Received: 13 May 2016 Accepted: 4 October 2016

\section{Published online: 13 October 2016}

\section{References}

1. McMurray JE, Cohen M, Angus G, Harding J, Gavel P, Horvath J, et al. Women in medicine: a four-nation comparison. J Am Med Womens Assoc. 2002;57(4):185-90

2. Jefferson L, Bloor K, Maynard A. Women in medicine: historical perspectives and recent trends. Br Med Bull. 2015;114(1):5-15.

3. Lundberg S, Rose E. The effects of sons and daughters on men's labor supply and wages. Rev Econ Stat. 2002;84(2):251-68.

4. Jones M. 'Mainstreaming' of less than full-time training. Anaesthesia. 2015; 70(6):641-4.

5. Cull WL, O'Connor KG, Olson LM. Part-time work among pediatricians expands. Pediatrics. 2010;125(1):152-7.

6. Heiligers PJM, Hingstman L. Career preferences and the work-family balance in medicine: gender differences among medical specialists. Soc Sci Med. 2000; 50(9):1235-46

7. Joyce CM, Wang WC, Cheng TC. Changes in doctors' working hours: a longitudinal analysis. Med Care Res Rev. 2015;72(5):605-21.

8. Dwan KM, Douglas KA, Forrest LE. Are "part-time" general practitioners workforce idlers or committed professionals? BMC Fam Pract. 2014;15:154.

9. Royal College of Radiologists. Sustainable future for diagnostic radiology: less than full-time (LTFT) working. London: Royal College of Radiologists, 2015:BFCR (15)10.

10. Buddeberg-Fischer B, Stamm M, Buddeberg C, Bauer G, Haemmig O, Knecht $M$, et al. The impact of gender and parenthood on physicians' careers - professional and personal situation seven years after graduation. BMC Health Serv. Res. 2010;10:40.

11. Levinson W, Lurie N. When most doctors are women: what lies ahead? Ann Intern Med. 2004;141(6):471-4.
12. Hedden L, Barer M, Cardiff K, McGrail K, Law M, Bourgeault I. The implications of the feminization of the primary care physician workforce on service supply: a systematic review. Hum Resour Health. 2014;12(1):32.

13. Wang C, Sweetman A. Gender, family status and physician labour supply. Soc Sci Med. 2013;94:17-25.

14. Parkhouse J. Doctors' careers: aims and experiences of medical graduates. London: Routledge; 1991.

15. de Jong JD, Heiligers P, Groenewegen PP, Hingstman L. Why are some medical specialists working part-time, while others work full-time? Health Policy. 2006;78(2-3):235-48

16. Woodward CA, Williams AP, Ferrier B, Cohen M. Time spent on professional activities and unwaged domestic work. Is it different for male and female primary care physicians who have children at home? Can Fam Physician. 1996:42:1928-35.

17. Gjerberg E. Women doctors in Norway: the challenging balance between career and family life. Soc Sci Med. 2003;57(7):1327-41.

18. Jacobson CC, Nguyen JC, Kimball AB. Gender and parenting significantly affect work hours of recent dermatology program graduates. Arch Dermatol. 2004;140(2):191-6.

19. Gravelle H, Hole AR. The work hours of GPs: survey of English GPs. Br J Gen Pract. 2007;57(535):96-100.

20. Nomura K, Gohchi K. Impact of gender-based career obstacles on the working status of women physicians in Japan. Soc Sci Med. 2012;75(9): $1612-6$.

21. Reed V, Buddeberg-Fischer B. Career obstacles for women in medicine: an overview. Med Educ. 2001;35(2):139-47.

22. Evans J, Goldacre MJ, Lambert TW. Views of UK medical graduates about flexible and part-time working in medicine: a qualitative study. Med Educ. 2000;34(5):355-62.

23. Jefferson L, Bloor K, Spilsbury K. Exploring gender differences in the working lives of UK hospital consultants. J R Soc Med. 2015:108(5):184-91.

24. Medical Women's Federation. Making part-time work: summary report. London: Medical Women's Federation; 2008.

25. Randive S, Johnston CL, Fowler AM, Evans CS. Influence of less than fulltime or full-time on totality of training and subsequent consultant appointment in anaesthesia. Anaesthesia. 2015;70(6):686-90.

26. Deloitte Centre for Health Solutions. Primary care: Today and tomorrow. London: The Deloitte Centre for Health Solutions; 2012.

27. Staiger DO, Auerbach DI, Buerhaus PI. Trends in the work hours of physicians in the United States. JAMA. 2010;303(8):747-53.

28. Stamm M, Buddeberg-Fischer B. How do physicians and their partners coordinate their careers and private lives? Swiss Med. Wkly. 2011;141: w13179.

29. Yong J, Wolfenden $\mathrm{H}$, Wheeler $\mathrm{K}$, Edge J. Do part time women doctors make a positive contribution to the NHS? BMJ Careers. BMJ Careers: The BMJ; 2015.

30. Mechaber HF, Levine RB, Manwell LB, Mundt MP, Linzer M, the MI. Part-time physicians... prevalent, connected, and satisfied. J Gen Intern Med. 2008; 23(3):300-3.

\section{Submit your next manuscript to BioMed Central and we will help you at every step:}

- We accept pre-submission inquiries

- Our selector tool helps you to find the most relevant journal

- We provide round the clock customer support

- Convenient online submission

- Thorough peer review

- Inclusion in PubMed and all major indexing services

- Maximum visibility for your research

Submit your manuscript at www.biomedcentral.com/submit 